\title{
Characteristics of a small colony variant of Pseudomonas putida F1 emerged from repetitive exposure to nanoscale zerovalent iron
}

\author{
Panaya Kotchaplai ${ }^{\mathrm{a}, \mathrm{b}}$, Eakalak Khan ${ }^{\mathrm{c}}$, Alisa S. Vangnai ${ }^{\mathrm{d}, \mathrm{e}, *}$ \\ a Institute of Biotechnology and Genetic Engineering, Chulalongkorn University, Bangkok 10330 Thailand \\ b International Program in Hazardous Substance and Environmental Management, Graduate School, \\ Chulalongkorn University, Bangkok 10330 Thailand \\ c Department of Civil and Environmental Engineering and Construction, University of Nevada, Las Vegas, \\ NV 89154-4015 USA \\ d Department of Biochemistry, Faculty of Science, Chulalongkorn University, Bangkok 10330 Thailand \\ e Biocatalyst and Environmental Biotechnology Research Unit, Department of Biochemistry, \\ Faculty of Science, Chulalongkorn University, Bangkok 10330 Thailand
}

*Corresponding author, e-mail: alisa.v@chula.ac.th

Received 23 Feb 2021

Accepted 17 Mar 2021

\begin{abstract}
While nanoscale zero valent iron (NZVI) is a promising alternative for in situ remediation, its potential environmental impact is a major concern. Herein, irreversible small colony variant (SCV) of Pseudomonas putida F1, obtained from the repetitive exposure to NZVI, was firstly reported. This SCV phenotype exhibited several altered characteristics including slower growth rate or longer lag phase, loss of swimming ability, and reduced biofilm formation. Regardless of reversibility, the persistence to gentamicin was used to distinguish the phenotypic variant from the normal phenotype and to further explore factors affecting this occurrence. By the third cycles of the repetitive exposure to 0.1 and $0.5 \mathrm{~g} / 1$ of NZVI, the frequency of the phenotypic variant increased by 67- and 342-times, in comparison to those of non-exposed cells, respectively. While the repetitive exposure to $0.5 \mathrm{~g} / \mathrm{l}$ of Fe(II) also resulted in the rising of the gentamicin-persistent phenotype by 65-fold by the third cycle of exposure, the repetitive exposure to either oxidized NZVI or Fe(III) did not induce the phenotypic variant. These results suggest that the emergence of this phenotype appears to associate with the NZVI-mediated oxidative stress. Together, this study suggests that the exposure to NZVI could trigger the emergence of phenotypic variants which could result in an environmental fitness trade-off.
\end{abstract}

KEYWORDS: nanoscale zero valent iron, repetitive exposure, phenotypic variant, environmental fitness trade-off

\section{INTRODUCTION}

Nanoscale zero valent iron (NZVI) is an extensively used nanoparticle for in situ remediation of contaminated sites. Due to its high reactivity and capability of generating oxidants, environmental impact of NZVI is highly concerned, especially on those indigenous microorganisms. Pseudomonas is one of the versatile environmental bacteria capable of adapting itself to several stress conditions [1]. Its versatility, particularly tolerance and ability to utilize various toxic hydrocarbon/pollutants as carbon source and ubiquity, makes it a major degrader in many polluted sites [1]. Pseudomonas putida F1 is a well-studied soil bacterium for the capability to degrade various aromatic hydrocarbons includ- ing toluene [2]. The toxicity of commercial NZVI was studied using this bacterial strain as a model strain [3]. While NZVI particles are toxic to P. putida $\mathrm{F} 1$, the cells can adapt themselves by modifying their membrane compositions to counteract the occurred stress. Interestingly, the repetitive exposure to $0.1 \mathrm{~g} / 1 \mathrm{NZVI}$, which is an environmental relevant level, induced the emergence of a reversible NZVI-persistent phenotype showing distinct smaller size and higher tolerance to NZVI [3]. However, the mechanism underlying the NZVI-induced phenotypic variation is still unclear. Recently, several studies reported the bacterial adaptation to chronic or repetitive exposure to metal/metal oxide nanoparticles resulting in higher tolerance to such nanoparticles [3-5]. Most of these studies focused 
on the tolerance and the adaptation mechanisms, and the reported tolerance of these strains were reversible. So far, only Mitchell et al [4] reported an irreversible phenotype of Shewanella oneidensis MR1 which is resistant to nanoparticles of a complex metal oxide (nickel manganese cobalt oxide, NMC) obtained from the chronic exposure to NMC.

In the environment, bacteria typically deal with dynamically fluctuated/challenged situations such as alterations in temperature and $\mathrm{pH}$, and the presence of xenobiotic compounds. Bacterial adaptability is, therefore, an important factor determining their survival. Bacterial adaptation can occur through many processes, for example, physiological alteration (e.g. modification in their membrane or protein expression) and/or genetic modification (e.g. mutation or DNA rearrangement). In some cases, these processes can lead to cross protection against other stresses [6]. While bacterial adaptation to cope with stresses is beneficial for their survival, some adaptation processes are metabolic burden or cause a disturbance to bacterial metabolism [7].

Phenotypic variation is one of the survival strategies adopted by bacteria during stress conditions. The phenotypic or phase variation is generated by mutation, DNA rearrangement or stochastically epigenetic changes, resulting in different physiological states of cells and granting them chances to survive under stress conditions such as antibiotic or oxidative stresses [8]. One of the most studied phenotypic variants is a small colony variant (SCV). Generally, the SCV phenotype is described as a slowgrowing subpopulation of bacteria exhibiting different characteristics (e.g. increasing resistance to antibiotics or higher biofilm formation), compared with the normal phenotype [9]. While the bacterial SCV phenotype is extensively studied in pathogenic bacteria due to the association with difficult-to-treat chronic infection caused by distinctive characteristics, the study on environmental microorganisms has been limited. Recently, a SCV has been reported to affect various characteristics of rhizospheric bacteria [9]. The SCV phenotype of Pseudomonas chlororaphis exhibited higher antibiotic resistance and biofilm formation, whereas bacterial motility and production of phenanzine decreased [9].

Along with a reported NZVI-persistent phenotype (i.e. reversible phenotypic variant) discovered by our research group [3], we are able to isolate an irreversible SCV phenotype (further mentioned as the SCV phenotype) of $P$. putida F1 during the repetitive exposure to NZVI. Since the SCV pheno- type showed higher antibiotic susceptibility than the normal phenotype of the P. putida F1, in this study, the antibiotic persistence was used as a surrogate to explore the NZVI-mediated emergence of phenotypic variants of $P$. putida F1 cells. In addition to its biodegradability, P. putida $\mathrm{F} 1$ also posses swimming motility and biofilm forming ability which facilitate the in situ remediation. Although the environmental relevant concentration of NZVI did not likely adversely affect the environmental bacteria in term of cell survival [3], the phenotypic variation may affect cell activities thus the efficiency of in situ remediation. Accordingly, such environmentally relevant characteristics, which are toluene sensitivity and degradation, swimming ability and biofilm formation of the SCV phenotype were studied in comparison to the normal phenotype.

\section{MATERIALS AND METHODS}

\section{Materials, bacterial strain, media, and cultivation conditions}

Nanofer 25S (NZVI from hereon) was purchased from NANOIRON s.r.o., Czech Republic. The characteristics of NZVI are as mentioned in Kotchaplai et al [3]. For bacterial cultivation, either the normal or the SCV phenotype of $P$. putida F1 was grown at $30^{\circ} \mathrm{C}, 200 \mathrm{rpm}$ in either tryptic soy broth (TSB) or M9 minimal medium as mentioned elsewhere [3]. Except where noted otherwise, $0.4 \%$ glucose was used as sole carbon source in minimal medium and designated as M9G.

\section{Effect of NZVI exposure on the phenotypic variant}

For NZVI exposure, 1\% v/v of overnight culture of $P$. putida F1 was transferred to M9G containing $0.1,0.5$, or $1.0 \mathrm{~g} / 1$ of NZVI and shaken at $30^{\circ} \mathrm{C}$, $150 \mathrm{rpm}$. After $24 \mathrm{~h}$ of NZVI exposure, $1 \% \mathrm{v} / \mathrm{v}$ of the NZVI-treated cell suspension was then transferred to fresh M9G containing the same NZVI concentration as previously mentioned. The exposures were repeated for at least three cycles. The frequency of the phenotypic variant detection in each cycle was determined using the plate count technique.

In a previous study, the phenotypic variant of P. putida F1 cells detected upon repetitive exposure to NZVI was indicated by the distinct smaller colony [3]. Due to the limitation of detecting the smaller colony occurred at low frequency, which could be hindered by the high amount of the normal cells, antibiotic resistance was selected as a surrogate for detecting the phenotypic variant. The 
antibiotic resistances of the normal and the SCV phenotype cells of $P$. putida F1 were tested as described in the supplementary materials (Fig. S1). While the growth of the normal cells of P. putida F1 was completely inhibited in the presence of $2 \mu \mathrm{g} / \mathrm{ml}$ of gentamicin, the stable SCV phenotype could persist to $4 \mu \mathrm{g} / \mathrm{ml}$ gentamicin. Thus, the phenotypic variant in this study, referred to as P. putida F1 cells, is able to grow on TSB agar plate containing $4 \mu \mathrm{g} / \mathrm{ml}$ of gentamicin. The frequency of the phenotypic variant was calculated using the following equation: frequency of the phenotypic variant $=$ (number of cells grown on TSB plate containing gentamicin)/total cell number.

The potential NZVI-mediated factors affecting the emergence of the SCV phenotype, i.e. oxidative stress, NZVI reactivity and iron species, were also investigated. In this experiment, $P$. putida $\mathrm{F} 1$ cells were repeatedly exposed to $\mathrm{H}_{2} \mathrm{O}_{2}$, oxidizedNZVI (O-NZVI), Fe(II) and Fe(III) (equivalent to exposure to $0.5 \mathrm{~g} / 1 \mathrm{NZVI}) . \mathrm{H}_{2} \mathrm{O}_{2}$ was used as a surrogate to assess the role of NZVI-mediated oxidative stress. To determine the equivalent intracellular oxidative stress, $P$. putida F1 cells from midexponential phase were collected, washed twice with $0.85 \% \mathrm{NaCl}$, and resuspended in M9G medium (initial cell concentration $\approx 10^{8} \mathrm{CFU} / \mathrm{ml}$ ). Stock solution of CM- $\mathrm{H}_{2}$ DCFDA (5-(and-6)-chloromethyl$2^{\prime}, 7^{\prime}$-dichlorodihydrofluorescein diacetate, acetyl ester) in dimethyl sulfoxide was added to the cell suspension to obtain a final concentration of $1 \mu \mathrm{M}$ of $\mathrm{CM}-\mathrm{H}_{2}$ DCFDA. Cell suspension was then incubated at $30^{\circ} \mathrm{C}$ in dark condition for $30 \mathrm{~min}$. After that, NZVI was added to obtain a final NZVI concentration of $0.5 \mathrm{~g} / 1$ and incubated at $200 \mathrm{rpm}$ and $30^{\circ} \mathrm{C}$ for $1 \mathrm{~h}$. Two hundred $\mu \mathrm{l}$ of NZVI-treated sample were transferred to a 96-well black plate, and fluorescence signals of CM- $\mathrm{H}_{2}$ DCFDA were detected using a Biotek microplate reader (Biotek Instruments, Inc) at excitation/emission wavelengths of $492 / 517 \mathrm{~nm}$. The level of intracellular oxidative stress induced by the exposure to $0.5 \mathrm{~g} / 1$ of NZVI was determined by comparing with the standard curve of those intracellular oxidative stress induced by various concentrations of $\mathrm{H}_{2} \mathrm{O}_{2}$.

\section{Characterization of the SCV phenotype}

\section{Bacterial growth rate}

An overnight culture of either the normal phenotype or the SCV phenotype of $P$. putida F1 cells was inoculated into $100 \mathrm{ml}$ of M9G or M9 with toluene in vapor phase (M9T), or TSB medium at $30^{\circ} \mathrm{C}$,
$150 \mathrm{rpm}$. The optical density (OD600) at each time point was collected and exponential growth rate $(\mu)$ was calculated according to Zeyer et al [10].

\section{Swimming motility}

Swimming motility is a flagella-based movement of bacteria in liquid of low-viscosity media [11]. Swimming ability of the normal and the SCV phenotype of P. putida F1 cells was tested according to MartinezGracia et al [11] with some modifications. Bacterial cells from the overnight culture were stabbed to the center of a TSB plate containing 0.3\% agar using sterile toothpick. Swimming zone size, as indicated by the radial halo zone within agar, was measured after $24 \mathrm{~h}$ of incubation at $30^{\circ} \mathrm{C}$.

\section{Biofilm formation}

An overnight culture of $P$. putida F1 was inoculated in fresh M9G medium, and biofilm was statically grown in a 24 -well polystyrene plate at $30^{\circ} \mathrm{C}$. At each time point, cell culture was removed by pipetting out, and wells were washed gently three times to remove loosely bound cells prior to air drying. The attached cells were recovered by resuspending in sterile DI water before serially diluted and plated on TSB agar. Biofilm amount was quantified by crystal violet staining [12].

\section{Toluene degradation}

Toluene degradation was studied using the normal and SCV cells acclimatized to toluene to reduce lag phase during the degradation. To prepare tolueneacclimatized cells, $P$ putida $\mathrm{F} 1$ cells were cultivated in $\mathrm{M} 9 \mathrm{~T}$ medium at $30^{\circ} \mathrm{C}, 150 \mathrm{rpm}$. Cells from midexponential phase were harvested by centrifugation at $5000 \mathrm{rpm}$ for $15 \mathrm{~min}$ and, then, washed twice with $0.85 \% \mathrm{NaCl}$ and resuspended in $\mathrm{M} 9 \mathrm{G}$ medium to initial OD600 of 0.05 . Toluene degradation test was conducted in 13-ml capped vial containing $2 \mathrm{ml}$ of cell culture and initial toluene concentration of $100 \mathrm{mg} / \mathrm{l}$. At each time point, vials were sacrificed for toluene quantification.

\section{Statistical analysis}

The effects of NVZI and other factors on the emergence of phenotypic variants were statistically analyzed using two-way analysis of variance (ANOVA) followed by Tukey's multiple comparisons ( $p<$ 0.05). Student $t$-test with Holm-Sidak method was used to evaluate the growth rate of the normal and 
the SCV phenotype of $P$. putida F1 cells under various conditions. All data were analyzed by GraphPad Prism software (GraphPad Prism 8 for Windows 64bit version 8.4.2, GraphPad Software, San Diego California USA, www.graphpad.com). All of the experiments were performed in triplicate. The data were presented as mean value \pm standard deviation.

\section{RESULTS AND DISCUSSION}

\section{Altered antibiotic susceptibility of the SCV phenotype}

The SCV phenotype of $P$. putida F1 was tested for its susceptibility to various antibiotics in order to distinguish the phenotypic variant from the normal phenotype. The NZVI-induced SCV phenotype was considerably more susceptible to ampicillin and chloramphenicol as indicated by the lower MIC (Table S1). On the contrary, the SCV phenotype showed a slightly higher tolerance to gentamicin, i.e., while the growth of wildtype P. putida $\mathrm{F} 1$ was completely inhibited at $4 \mu \mathrm{g} / \mathrm{ml}$ gentamicin, a considerable growth of the SCV phenotype, i.e. OD600 of 0.2 at the 24 th $h$ was detected at that concentration. In the subsequent experiments, the tolerance to gentamicin was, therefore, used to indicate the altered phenotype of bacterial cells exposed to NZVI.

Nanoparticles of metal oxides, i.e. nano- $\mathrm{Al}_{2} \mathrm{O}_{3}$ and nano- $\mathrm{ZnO}$ as well as their corresponding metal ions, could induce the occurrence of phenotypic variant of Escherichia coli K-12 with higher resistance to antibiotics [5]. Similarly, the frequency of resistant strain was determined by the ratio of cells growing on the plate containing antibiotic and the total cell number [5]. On the contrary to our study, the obtained variants were more resistant to ciprofloxacin, chloramphenicol, tetracycline, and ampicillin [5]. Only the $\mathrm{Al}^{2+}$-induced variant was more resistant to gentamicin with two-fold higher MIC [5]. The changes in antibiotic resistant profiles of these variants were proposed to be attributed to oxidative stress-mediated genetic mutation [5].

\section{Increasing of the gentamicin-persistent cells induced by NZVI exposure}

The background level or the frequency of the gentamicin-persistent cells during the sub-culturing in the NZVI-free condition remained approximately $10^{-6}$ to $10^{-5}$ throughout the study. The single exposure to $0.1 \mathrm{~g} / 1 \mathrm{NZVI}$ did not affect the amount of the gentamicin-persistent cells (0.6-fold higher than those of non-exposed cells). However, the repetitive exposure to $0.1 \mathrm{~g} / 1 \mathrm{NZVI}$ significantly

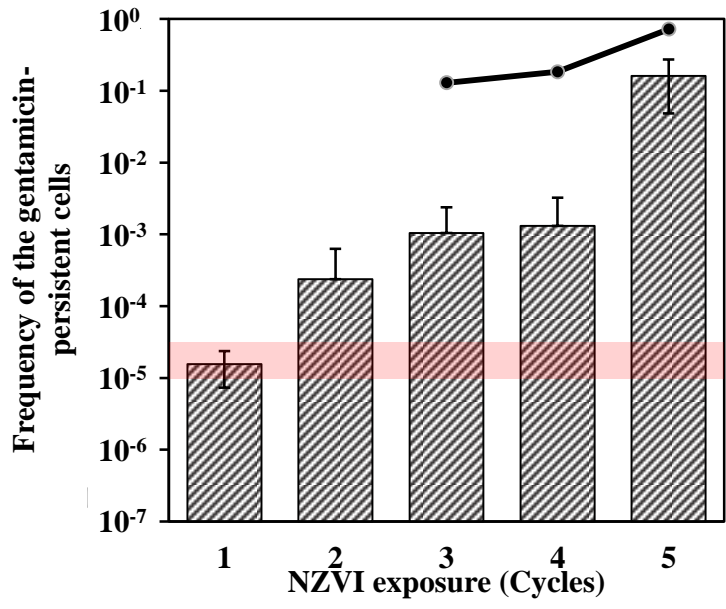

Fig. 1 Emergence of phenotypic variant of P. putida F1 upon repetitive exposure to $0.1 \mathrm{~g} / 1$ NZVI. Bar graphs indicate the frequency of the gentamicin-persistent cells. Line graph represents the frequency of the phenotypic variant showing distinct smaller colony size. Pink strip indicates range of the frequency of the control gentamicinpersistent cells. The data are based on mean and standard deviation of at least 3 experimental replications. Some error bars are missing due to the large value of lower SD exceeding the log scale.

increased the frequency of the gentamicin-persistent cells from $1.56 \times 10^{-5}$ in the first cycle to 0.0010 (67-fold), 0.0013 (84-fold), and 0.16 (10346-fold) by the third, fourth, and fifth cycle (adjusted $p<$ 0.0001), respectively (Fig. 1). During these cycles, the frequency of the altered bacterial phenotype, i.e. small colony, is high enough to be visually detectable $(0.72 \pm 0.14$ in the 5 th cycle). This result is similar to the previously reported distinct NZVI-induced small colony which was approximately $75 \%$ by the 5th cycle [3].

It is likely that bacterial response to NZVI exposure (i.e. alteration in their membrane [3]) may provide cross-protection against gentamicin. Prolonged exposures to nanoparticles allow bacterial cells to adapt themselves to the occurred damages, resulting in either phenotypic or genotypic changes in cells [13]. The nanoparticle-induced adaptations include membrane modification, induction of stress response systems, and shifts in bacterial metabolism. These alterations can cause a crossresistance between nanoparticles and antibiotics and are becoming a major concern [13]. In addition to drug resistance, the prolonged nanoparticle exposure also promotes bacterial pathogenicity [13]. 


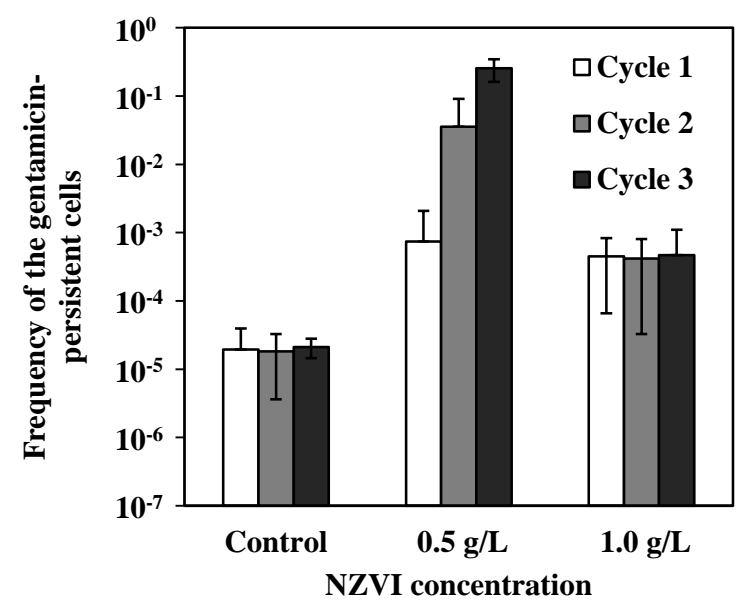

Fig. 2 The concentration-dependent effect of NZVI on the rising of the gentamicin-persistent phenotype of $P$. putida F1. The data are based on mean and standard deviation of at least 3 experimental replications. Some error bars are missing due to the large value of lower SD exceeding the log scale.

Beside adaptation, the NZVI exposure may create a selection pressure toward subpopulation of $P$. putida F1 cells which can persist gentamicin exposure.

On the contrary to the SCV phenotype, the ability to grow in the presence of $4 \mu \mathrm{g} / \mathrm{ml}$ gentamicin of the obtained phenotypic variant from this experiment is transient. Once cultured in the NZVI-free medium, the phenotypic variant can resume their normal size and becomes susceptible to $4 \mu \mathrm{g} / \mathrm{ml}$ gentamicin (data not shown). The reversible phenotypic variant appears to be less concerning than the irreversible phenotype; however, the transient cross-stress tolerance was reported to facilitate bacterial evolution of antibiotic resistance [14].

The NZVI-induced emergence of the gentamicinpersistent cells is NZVI concentration-dependent

The increased gentamicin-persistent phenotype appears to depend on the NZVI concentration (Fig. 2). Compared with the control, i.e. non-exposed cells, the single exposure to 0.5 and $1.0 \mathrm{~g} / 1 \mathrm{NZVI}$ increased the frequency of the gentamicin-persistent cells by approximately 38 -fold and 23 -fold, respectively (Fig. 2). Similar to those repeatedly exposed to $0.1 \mathrm{~g} / 1 \mathrm{NZVI}$ (Fig. 1), the repetitive exposure to $0.5 \mathrm{~g} / 1 \mathrm{NZVI}$ significantly induced the emergence of gentamicin-persistent cells $(p<0.01)$. The frequency of the gentamicin-persistent cells increased from 0.0007 (single exposure to $0.5 \mathrm{~g} / \mathrm{l} \mathrm{NZVI)} \mathrm{to}$ 0.254 (342-fold) by the 3rd cycle of exposure to
$0.5 \mathrm{~g} / 1 \mathrm{NZVI}$. Interestingly, the repetitive exposure to $1.0 \mathrm{~g} / 1 \mathrm{NZVI}$ did not significantly induce the emergence of the gentamicin-persistent cells. The frequency of the persister cells remained approximately $10^{-4}$ to $10^{-3}$ upon 3 cycles of exposure to $1.0 \mathrm{~g} / 1 \mathrm{NZVI}$.

The toxicity assessments of nanoparticles majorly focused on the high concentration range due to the expectable adverse effects, e.g. distinctive cell injuries or cell death. However, upon in situ application, the introduced nanoparticles, particularly NZVI, were likely diluted. Based on cell survival, the toxicity of single exposure to 0.1 to $1.0 \mathrm{~g} / 1$ NZVI seems negligible since cells can resume their growth upon prolonged exposure [3]. The repetitive NZVI exposures, nonetheless, induce a notable dosedependent alteration in bacterial phenotype. While the mechanism is still unclear, the accumulation of iron (carry-over of NZVI) during repetitive NZVI exposure may play role in the increasing frequency of the SCV phenotype. However, high concentrations of NZVI $(\geqslant 1.0 \mathrm{~g} / \mathrm{l})$ may cause an unbearable damage; for example, severe membrane damage and oxidative stress, resulting in cell death. This may explain the limited induction of the SCV phenotype by repetitive exposure to $1.0 \mathrm{~g} / \mathrm{l} \mathrm{NZVI}$.

The emergence of the SCV phenotype is induced by NZVI-mediated oxidative stress

The toxicity of NZVI is attributed to physical contact, oxidative stress, and the released Fe(II) [15]. The potential factors affecting the emergence of the phenotypic variant, i.e. oxidative stress as well as the released iron ions, were investigated. $\mathrm{CM}-\mathrm{H}_{2}$ DCFDA was used to determine the level of the intracellular oxidative stress induced by NZVI exposure. The exposure to $0.5 \mathrm{~g} / 1 \mathrm{NZVI}$ generated the comparable intracellular oxidative stress with those exposed to $0.5 \pm 0.03 \mathrm{mM} \mathrm{H}_{2} \mathrm{O}_{2}$. The exposure to $0.5 \mathrm{~g} / \mathrm{l}$ of O-NZVI resulted in the comparable intracellular oxidative stress with those exposed to $0.09 \pm 0.01 \mathrm{mM}$ $\mathrm{H}_{2} \mathrm{O}_{2}$. Accordingly, the exposure to $0.5 \mathrm{mM} \mathrm{H}_{2} \mathrm{O}_{2}$ was used as the surrogate for the oxidative stress induced by exposure to $0.5 \mathrm{~g} / 1 \mathrm{NZVI}$. The total cell number of $P$. putida F1 exposed to either O-NZVI, $\mathrm{H}_{2} \mathrm{O}_{2}, \mathrm{Fe}(\mathrm{II})$, or $\mathrm{Fe}$ (III) for $24 \mathrm{~h}$ was approximately $10^{9}$ to $10^{10} \mathrm{CFU} / \mathrm{ml}$ throughout the study indicating no difference in the total cell numbers.

In comparison to un-exposed cells, the single exposure to $0.5 \mathrm{mM} \mathrm{H}_{2} \mathrm{O}_{2}$ increased the detection frequency of gentamicin-persistent cells by 14.5 -fold $\left(2.04 \times 10^{-4}\right)$ (Fig. 3). The exposure to $0.5 \mathrm{~g} / 1$ of O-NZVI, Fe(II), and Fe(III) resulted in changes in 


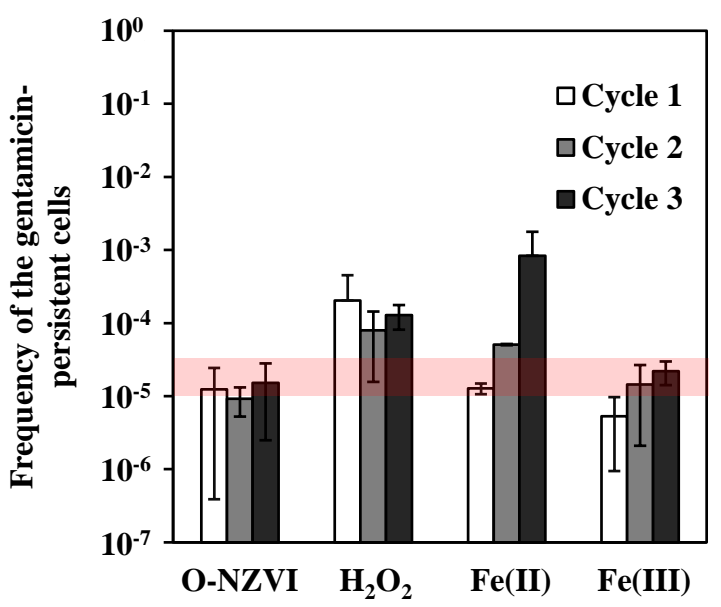

Fig. 3 The factors affecting the rising of the gentamicinpersistent phenotype of $P$. putida F1. Pink strip indicates range of the frequency of the control gentamicinpersistent cells. The data are based on mean and standard deviation of at least 3 experimental replications. Some error bars are missing due to the large value of lower SD exceeding the log scale.

the frequency of gentamicin-persister by approximately $0.8,0.9$, and 0.4-fold, respectively. However, the repetitive exposure to $\mathrm{H}_{2} \mathrm{O}_{2}$ did not further increase the frequency of the gentamicin-persistent phenotype, suggesting the maximum SCV induction caused by single exposure to $0.5 \mathrm{mM} \mathrm{H}_{2} \mathrm{O}_{2}$. The discrepancy between the repetitive exposure to NZVI and $\mathrm{H}_{2} \mathrm{O}_{2}$ is likely due to carry-over of NZVI during the repetitive exposure which can generate greater oxidative stress in the subsequent exposure. Only the repetitive exposure to $0.5 \mathrm{~g} / \mathrm{l} \mathrm{Fe}(\mathrm{II})$ induced the rising of the gentamicin-persistent phenotype. The exposure to $\mathrm{Fe}(\mathrm{II})$ for 3 cycles significantly increased the frequency of gentamicin-persister $\left(8.31 \times 10^{-4}\right.$, adjusted $p<0.0001$ ), compared with 1 and 2 cycles of exposure. Neither O-NZVI nor Fe(III) exposure affected the emergence of this phenotype. Taken together, these results indicate that the exposure to NZVI likely influences the emergence of the SCV phenotype through the mediation of oxidative stress. The repetitive exposure to $\mathrm{Fe}(\mathrm{II})$, which can interact with intracellular $\mathrm{H}_{2} \mathrm{O}_{2}$ and generate $\mathrm{OH}$. via Fenton reaction, also induce the emergence of SCV phenotype.

Typically, reactive oxygen species (ROS), such as $\mathrm{H}_{2} \mathrm{O}_{2}$ and $\mathrm{O}_{2}^{-}$, can be generated intracellularly as a byproduct from bacterial aerobic respiration or the oxidation of biomolecules [16]. $\mathrm{H}_{2} \mathrm{O}_{2}$ can further rapidly interact with Fe(II) (Fenton reaction), generating highly reactive, non-selective hydroxyl radicals which can further damage DNA and proteins [17]. The presence of NZVI or Fe(II) significantly promoted the Fenton-mediated oxidative damage, thus increasing chance of phenotypic variation or stress-response induced tolerance against gentamicin. Unlike the reactive iron nanoparticles, the iron oxide nanoparticle can interact with the biomolecules, yet, non-toxic to cells [18]. Even though Fe(III) and O-NZVI (which mainly consists of $\mathrm{Fe}(\mathrm{III})$ ) can also interact with $\mathrm{O}_{2}^{-}$. or $\mathrm{H}_{2} \mathrm{O}_{2}$ resulting in $\mathrm{Fe}(\mathrm{II})$ and oxygen, the lower impact of $\mathrm{Fe}(\mathrm{III})$ on bacterial cells is likely due to their low solubility, thus reducing their bioavailability [19].

Oxidative stress, i.e. $\mathrm{H}_{2} \mathrm{O}_{2}$-induced DNA damage, has also been reported to trigger and selected for the stable gentamicin-resistant SCV phenotype of Staphylococcus aureus [20]. Oxidative DNA damage (e.g. double stranded DNA breaking) could lead to mutated bacterial cells [21]. On the contrary, the expression of error-prone polymerase, a low fidelity DNA damage repairing enzyme, could enhance the mutation rate of bacteria, and might increase the frequency of the SCV phenotype [22]. While the oxidative stress-induced mutation likely explains the emergence of the irreversible SCV phenotype, there has been no reported mutagenicity effect of NZVI on bacterial cells [23]. Schiwy et al [23] studied the mutagenicity of aged Nanofer $25 \mathrm{~S}$ and reported that no mutagenicity was observed due to low ROS generation. Beside mutagenesis, the oxidative stress-induced expression of efflux pump and bacterial adaptation to membrane-active compounds have been reported to induce the cross-protection against aminoglycoside antibiotics [24,25]. For instance, Kurenbach et al [25] reported that bacterial exposure to a sublethal concentration of herbicides affected the susceptibility to various antibiotics through activation of soxS-controlled efflux pump. The soxRS regulon controls several proteins involved in bacterial oxidative stress response including superoxide dismutase, fumarase, and aconitase [26]. A peroxide-induced MexXY-OprM efflux pump system has been reported to play a role in the emergence of aminoglycoside resistant cells of P. aeruginosa [24].

The NZVI-induced SCV phenotype partially lost their environmental fitness-related traits

The SCV phenotype exhibited different growth patterns (e.g. lag time and growth rate) from those of the normal phenotype of $P$. putida F1 (Table 1). The 
Table 1 Growth of $P$ p putida F1 in various media.

\begin{tabular}{|c|c|c|c|c|}
\hline \multirow{2}{*}{ Condition } & \multicolumn{2}{|c|}{ Normal phenotype } & \multicolumn{2}{|c|}{ The SCV phenotype } \\
\hline & Lag time $(\mathrm{h})$ & Growth rate $\left(h^{-1}\right)$ & Lag time (h) & Growth rate $\left(\mathrm{h}^{-1}\right)$ \\
\hline TSB & 2 & $0.248 \pm 0.011$ & 2 & $0.217 \pm 0.015$ \\
\hline M9G & 2 & $0.213 \pm 0.026$ & $2-7$ & $0.243 \pm 0.080$ \\
\hline M9T + 0.1\% Glucose & 2 & $0.211 \pm 0.009$ & $13-24$ & $0.067 \pm 0.051^{*}$ \\
\hline M9T (Non-induced) & $6-7$ & $0.084 \pm 0.024$ & $24-57$ & $0.089 \pm 0.030$ \\
\hline M9T (Induced) & 2 & $0.220 \pm 0.051$ & 2 & $0.230 \pm 0.040$ \\
\hline
\end{tabular}

Asterisk indicates a significant difference $(p<0.01)$ between row, i.e. growth rate of the normal phenotype and the SCV phenotype of $P$ putida F1 in medium according to the Student $t$-test with the Holm-Sidak method.

growth rate of the SCV phenotype in TSB medium substantially dropped compared with the normal phenotype. On the contrary, while growth rates of the two phenotypes in minimal medium supplemented with glucose are comparable, lag phase of the SCV phenotype is slightly longer. P. putida F1 is a well-studied strain for its toluene degradability. In minimal medium, except for M9T inoculated with toluene-acclimated cells, the duration of lag phase of the SCV phenotype was much longer than that of the normal phenotype (Table 1). The SCV phenotype may become more susceptible to toluene and requires longer time to adapt to toluene, resulting in longer lag phase (at least $24 \mathrm{~h}$ ) for growth under toluene as a sole carbon source compared with 6$\mathrm{h}$ lag phase of the normal phenotype. Despite the four-fold longer lag phase, the maximum growth rate of the SCV phenotype was not significantly different from the normal cells, indicating that once SCV cells is acclimated to toluene, they are as effective as the normal cells for toluene utilization. This was confirmed by the growth of toluene-acclimated normal and SCV cells in M9T which exhibit similar lag phase and maximum growth rate (Table 1). Bacterial growth under toluene as a sole carbon source was also examined in the presence of glucose as a co-substrate. The addition of glucose reduced the duration of lag phase and the maximum growth rate of the normal phenotype in M9T. Even though the added glucose could substantially cut down the lag period of the SCV phenotype in M9T; the maximum growth rate was significantly lower than that of the normal phenotype (adjusted $p<0.0001$ ) and remained comparable to the case of M9T without glucose supplementation. P. putida can utilize toluene and glucose simultaneously [27]. Glucose is a source of carbon and energy for cells during adaptation to toluene, resulting in shorter lag time, compared with cells grew in M9T. Once glucose was completely consumed, cells grew solely on toluene.
Accordingly, the SCV phenotype, which is likely more susceptible to toluene or could utilize toluene at slower rate than the normal phenotype, exhibited a comparable growth rate of those cells grew in M9T without acclimation. Toluene degradation by the normal and the SCV phenotypes was tested at initial toluene concentration of $100 \mathrm{mg} / \mathrm{l}$, which did not inhibit the viability of both phenotypes. Even though the growth of toluene-acclimated SCV cells is comparable to the growth of normal $P$. putida F1 cells, the toluene degradation is substantially slower than the normal phenotype (Fig. 4a).

Substrates, such as hydrocarbon, can transport across membrane via three mechanisms: (1) passive diffusion, (2) passive facilitated diffusion, and (3) active transportation [28]. In our previous study, $P$. putida F1 cells could adapt to NZVI exposure by modifying their membrane composition, resulting in phenotypic variant with more rigid membrane [3]. This rigid membrane might reduce solvent influx [29]. The limited passive diffusion of toluene might reduce availability of toluene for utilization, thus contributing to the slower growth rate under toluene as carbon sources or slower toluene degradation of the SCV phenotype of $P$. putida F1. The altered membrane fluidity could affect the interaction between membrane lipids and proteins including efflux pumps [30]. As a result, extrusion, reduction, and degradation of toluene were affected.

The limited/low bioavailability of pollutant is one of the limitations for in-situ bioremediation process [31]. Chemotactic bacteria, for instance, Pseudomonas strains are capable of moving in responses to several pollutants, thus enhancing their bioavailability [32] and providing advantages over nonchemotactic or non-motile bacteria $[33,34]$. After sensing a chemical via chemoreceptor protein, bacteria can respond by moving toward chemoattractant, or moving away from chemorepellent by using 

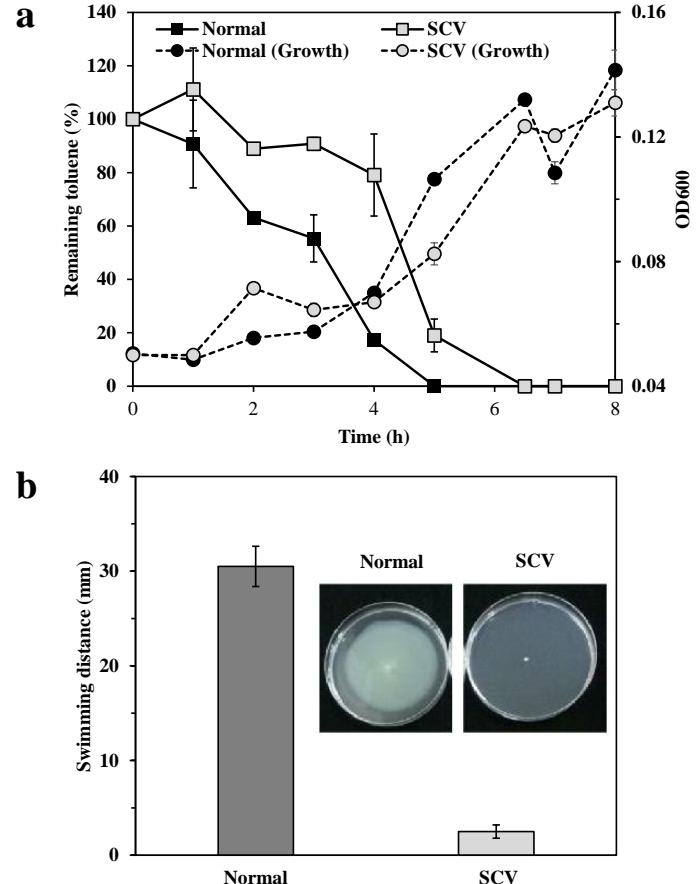

c

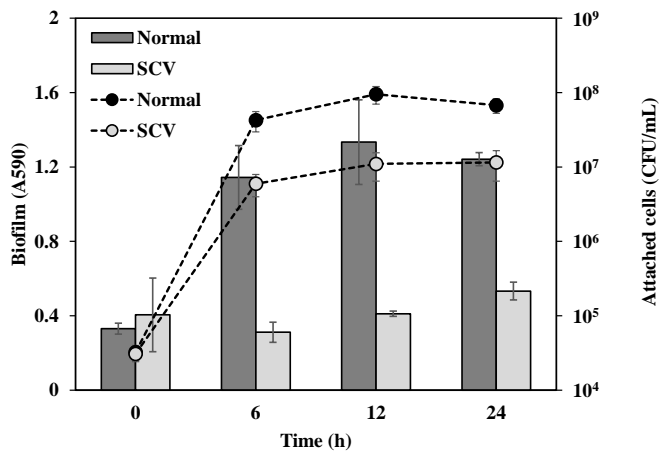

Fig. 4 Characteristics of the SCV phenotype in comparison to the normal phenotype of P. putida F1: (a) Toluene degradation by toluene-acclimated $P$. putida $\mathrm{F} 1$ cells. The normal phenotype is indicated by dark gray color and the SCV phenotype by light gray color; (b) Bacterial motility based on halo zone in the swimming plate assay; and (c) Biofilm formation of the normal phenotype (dark gray bars) and the SCV phenotype (light gray bars). The line graphs are the number of attached cells. The data are based on mean and standard deviation of at least 2 experimental replications.

flagellar-mediated swimming motility. P. putida F1 has been reported for their chemotactic ability toward several pollutants including benzene, toluene, and trichloroethylene [35]. However, the SCV phenotype of $P$. putida $\mathrm{F} 1$ is defective in swimming motility (Fig. 4b). This could strain chemotactic ability of the bacteria, thus, decreasing bioavailability to pollutants and their biodegradability. Even though the mechanism underlying the non-motility of the SCV phenotype is still unclear, the disturbance in the flagella synthesis or their function is likely to be the cause. A non-motile phenotype of P. putida with a mutation in flagella biosynthesis has been reported to become sensitive to toluene exposure due to a decreased efflux pump activity [36].

Bacterial motility/chemotaxis also affects biofilm formation, which can further affects the biodegradability [37]. Biofilm is a complex form of bacteria consisting of surface-associated bacterial cells held together by the matrix consisting of extracellular polymeric substance (EPS). It is a typical form of bacteria, which plays important roles in many biological processes, in the environment $[38,39]$. The effective biodegradation of pollutants by $P$. putida F1 biofilm has been reported [40]. The flagella-mediated swimming bacteria reach the surface forming mono-layer of attached bacteria. On the other hand, in the absence of flagella, the bacterial biofilm forming ability is increased due to the reduced mobility, thus, enhancing the number of attached cells. In this study, the amount of attached SCV phenotype cells was still high $\left(\approx 10^{7} \mathrm{CFU} / \mathrm{ml}\right)$, which was one-order of magnitude lower to that of the normal phenotype (Fig. 4c). However, no biofilm production was detected by using crystal violet staining method (Fig. 4c). This result suggests the disturbance in EPS production or secretion.

\section{CONCLUSION}

In this study, the stable NZVI-induced phenotypic variant of $P$. putida F1 was reported. Concomitantly with the slightly higher resistance to gentamicin, this phenotype was more susceptible to toluene, lost their swimming motility, and had no ability to form biofilm. Using gentamicin as a surrogate to distinguish the phenotypic variant from the normal phenotype of $P$. putida F1 revealed that the emergence of this phenotypic depended on the concentration of NZVI and the repetitiveness (cycle of exposure). The NZVI-induced oxidative stress mainly contributed to the induction of the SCV phenotype since the non-reactive form of NZVI (O-NZVI), as well as Fe(III), did not cause the emergence of the phenotype. Several integrations between NZVI and bacterial cells to improve the efficiency of remediation processes, both ex situ and in situ, have been reported. This study wanted to emphasize that bacterial cells could play an important role in biodegra- 
dation/biotransformation and, hence, might be able to adapt and survive in the presence of NZVI. The repetitive or chronic exposure to NZVI could result in a trade-off, as indicated by partial loss of bacterial environmental fitness. This should be taken as a concern when designing environmental application of NZVI to improve the efficiency of the process and to avoid the unintended consequence. The mechanism underlying the emergence of phenotypic variants should further explored to obtain a better understanding. Future studies should consider the effect of modified NZVIs, such as metal-doped NZVI, since they also release other metal ions.

\section{Appendix A. Supplementary data}

Supplementary data associated with this article can be found at http://dx.doi.org/10.2306/ scienceasia1513-1874.2021.044.

Acknowledgements: This research was financially supported by the Thailand Research Fund through the Royal Golden Jubilee PhD Program (Grant No. PHD/0359/2551). The results in this work are a part of Panaya Kotchaplai's Doctoral Dissertation at Chulalongkorn University.

\section{REFERENCES}

1. Udaondo Z, Duque E, Fernandez M, Molina L, de la Torre J, Bernal P, Niqui JL, Pini C, et al (2012) Analysis of solvent tolerance in Pseudomonas putida DOT$\mathrm{T} 1 \mathrm{E}$ based on its genome sequence and a collection of mutants. FEBS Lett 586, 2932-2938.

2. Reardon KF, Mosteller DC, Bull Rogers JD (2000) Biodegradation kinetics of benzene, toluene, and phenol as single and mixed substrates for Pseudomonas putida F1. Biotechnol Bioeng 69, 385-400.

3. Kotchaplai P, Khan E, Vangnai AS (2017) Membrane alterations in Pseudomonas putida F1 exposed to nanoscale zerovalent iron: Effects of short-term and repetitive NZVI exposure. Environ Sci Technol 51, 7804-7813.

4. Mitchell SL, Hudson-Smith NV, Cahill MS, Reynolds BN, Frand SD, Green CM, Wang C, Hang MN, et al (2019) Chronic exposure to complex metal oxide nanoparticles elicits rapid resistance in Shewanella oneidensis MR-1. Chem Sci 10, 9768-9781.

5. Zhang Y, Gu AZ, Xie S, Li X, Cen T, Li D, Chen J (2018) Nano-metal oxides induce antimicrobial resistance via radical-mediated mutagenesis. Environ Int 121, 1162-1171.

6. Rangel DE (2011) Stress induced cross-protection against environmental challenges on prokaryotic and eukaryotic microbes. World J Microbiol Biotechnol 27, 1281-1296.
7. Handel N, Schuurmans JM, Brul S, ter Kuile BH (2013) Compensation of the metabolic costs of antibiotic resistance by physiological adaptation in Escherichia coli. Antimicrob Agents Chemother 57, 3752-3762.

8. van den Broek D, Bloemberg GV, Lugtenberg B (2005) The role of phenotypic variation in rhizosphere Pseudomonas bacteria. Environ Microbiol 7, 1686-1697.

9. Wang D, Dorosky RJ, Han CS, Lo CC, Dichosa AE, Chain PS, Yu JM, Pierson LS 3rd, et al (2015) Adaptation genomics of a small-colony variant in a Pseudomonas chlororaphis 30-84 biofilm. Appl Environ Microbiol 81, 890-899.

10. Zeyer J, Wasserfallen A, Timmis KN (1985) Microbial mineralization of ring-substituted anilines through an ortho-cleavage pathway. Appl Environ Microbiol 50, 447-453.

11. Martinez-Garcia E, Nikel PI, Chavarria M, de Lorenzo $\mathrm{V}$ (2014) The metabolic cost of flagellar motion in Pseudomonas putida KT2440. Environ Microbiol 16, 291-303.

12. Thuptimdang P, Limpiyakorn T, McEvoy J, Pruss BM, Khan E (2015) Effect of silver nanoparticles on Pseudomonas putida biofilms at different stages of maturity. J Hazard Mater 290, 127-133.

13. Zhang C, Sun R, Xia T (2020) Adaption/resistance to antimicrobial nanoparticles: Will it be a problem? Nano Today 34, ID 100909.

14. Yin $\mathrm{H}$, Li G, Chen $\mathrm{X}$, Wang W, Wong PK, Zhao H, An T (2020) Accelerated evolution of bacterial antibiotic resistance through early emerged stress responses driven by photocatalytic oxidation. Appl Catal B Environ 269, ID 118829.

15. Lv Y, Niu Z, Chen Y, Hu Y (2017) Bacterial effects and interfacial inactivation mechanism of nZVI/Pd on Pseudomonas putida strain. Water Res 115, 297-308.

16. Cabiscol E, Tamarit J, Ros J (2000) Oxidative stress in bacteria and protein damage by reactive oxygen species. Int Microbiol 3, 3-8.

17. Sevcu A, El-Temsah YS, Joner EJ, Cernik M (2011) Oxidative stress induced in microorganisms by zerovalent iron nanoparticles. Microbes Environ 26, 271-281.

18. Mekseriwattana W, Srisuk S, Tantiapibalkun Y, Prapainop K (2019) Preparation of superparamagnetic iron oxide nanoparticles and investigation of their interaction with cells. ScienceAsia 45, 60-64.

19. Krewulak KD, Vogel HJ (2008) Structural biology of bacterial iron uptake. Biochim Biophys Acta 1778, 1781-1804.

20. Painter KL, Strange E, Parkhill J, Bamford KB, Armstrong-James D, Edwards AM (2015) Staphylococcus aureus adapts to oxidative stress by producing $\mathrm{H}_{2} \mathrm{O}_{2}$-resistant small-colony variants via the SOS response. Infect Immun 83, 1830-1844.

21. Boles BR, Singh PK (2008) Endogenous oxida- 
tive stress produces diversity and adaptability in biofilm communities. Proc Natl Acad Sci USA 105, 12503-12508.

22. Torres-Barcelo C, Cabot G, Oliver A, Buckling A, Maclean RC (2013) A trade-off between oxidative stress resistance and DNA repair plays a role in the evolution of elevated mutation rates in bacteria. Proc Biol Sci 280, ID 20130007.

23. Schiwy A, Maes HM, Koske D, Flecken M, Schmidt KR, Schell H, Tiehm A, Kamptner A, et al (2016) The ecotoxic potential of a new zero-valent iron nanomaterial, designed for the elimination of halogenated pollutants, and its effect on reductive dechlorinating microbial communities. Environ Pollut 216, 419-427.

24. Fraud S, Poole K (2011) Oxidative stress induction of the MexXY multidrug efflux genes and promotion of aminoglycoside resistance development in Pseudomonas aeruginosa. Antimicrob Agents Chemother 55, 1068-1074.

25. Kurenbach B, Marjoshi D, Amabile-Cuevas CF, Ferguson GC, Godsoe W, Gibson P, Heinemann JA (2015) Sublethal exposure to commercial formulations of the herbicides dicamba, 2,4-dichlorophenoxyacetic acid, and glyphosate cause changes in antibiotic susceptibility in Escherichia coli and Salmonella enterica serovar Typhimurium. mBio 6, ID 00009-15.

26. Demple B (1996) Redox signaling and gene control in the Escherichia coli soxRS oxidative stress regulon: A review. Gene 179, 53-57.

27. del Castillo T, Ramos JL (2007) Simultaneous catabolite repression between glucose and toluene metabolism in Pseudomonas putida is channeled through different signaling pathways. $J$ Bacteriol 189, 6602-6610.

28. Hua F, Wang HQ (2014) Uptake and trans-membrane transport of petroleum hydrocarbons by microorganisms. Biotechnol Biotechnol Equip 28, 165-175.

29. Kusumawardhani H, Hosseini R, de Winde JH (2018) Solvent Tolerance in Bacteria: Fulfilling the Promise of the Biotech Era? Trends Biotechnol 36, 1025-1039.

30. Adebusuyi AA, Foght JM (2011) An alternative phys- iological role for the EmhABC efflux pump in Pseudomonas fluorescens cLP6a. BMC Microbiol 11, ID 252.

31. Singh R, Paul D, Jain RK (2006) Biofilms: implications in bioremediation. Trends Microbiol 14, 389-397.

32. Parales RE, Luu RA, Hughes JG, Ditty JL (2015) Bacterial chemotaxis to xenobiotic chemicals and naturally-occurring analogs. Curr Opin Biotechnol 33, 318-326.

33. Marx RB, Aitken MD (2000) Bacterial chemotaxis enhances naphthalene degradation in a heterogeneous aqueous system. Environ Sci Technol 34, 3379-3383.

34. Paul D, Singh R, Jain RK (2006) Chemotaxis of Ralstonia sp. SJ98 towards p-nitrophenol in soil. Environ Microbiol 8, 1797-1804.

35. Parales RE, Ditty JL, Harwood CS (2000) Toluenedegrading bacteria are chemotactic towards the environmental pollutants benzene, toluene, and trichloroethylene. Appl Environ Microbiol 66, 4098-4104.

36. Segura A, Duque E, Hurtado A, Ramos JL (2001) Mutations in genes involved in the flagellar export apparatus of the solvent-tolerant Pseudomonas putida DOT-T1E strain impair motility and lead to hypersensitivity to toluene shocks. J Bacteriol 183, 4127-4133.

37. Pande V, Pandey SC, Sati D, Pande V, Samant M (2020) Bioremediation: an emerging effective approach towards environment restoration. Env Sustain 3, 91-103.

38. Davey ME, O'Toole GA (2000) Microbial biofilms: from ecology to molecular genetics. Microbiol $\mathrm{Mol}$ Biol Rev 64, 847-867.

39. Fahruddin F, Johannes E, Dwyana Z (2019) Antifouling potential of Thalassia hemprichii extract against growth of biofilm-forming bacteria. ScienceAsia 45 , 21-27.

40. Woo H, Sanseverino J, Cox CD, Robinson KG, Sayler GS (2000) The measurement of toluene dioxygenase activity in biofilm culture of Pseudomonas putida F1. J Microbiol Methods 40, 181-191. 
Appendix A. Supplementary data

Transferred one colony of WT or SCV cells to 5-mL TSB medium

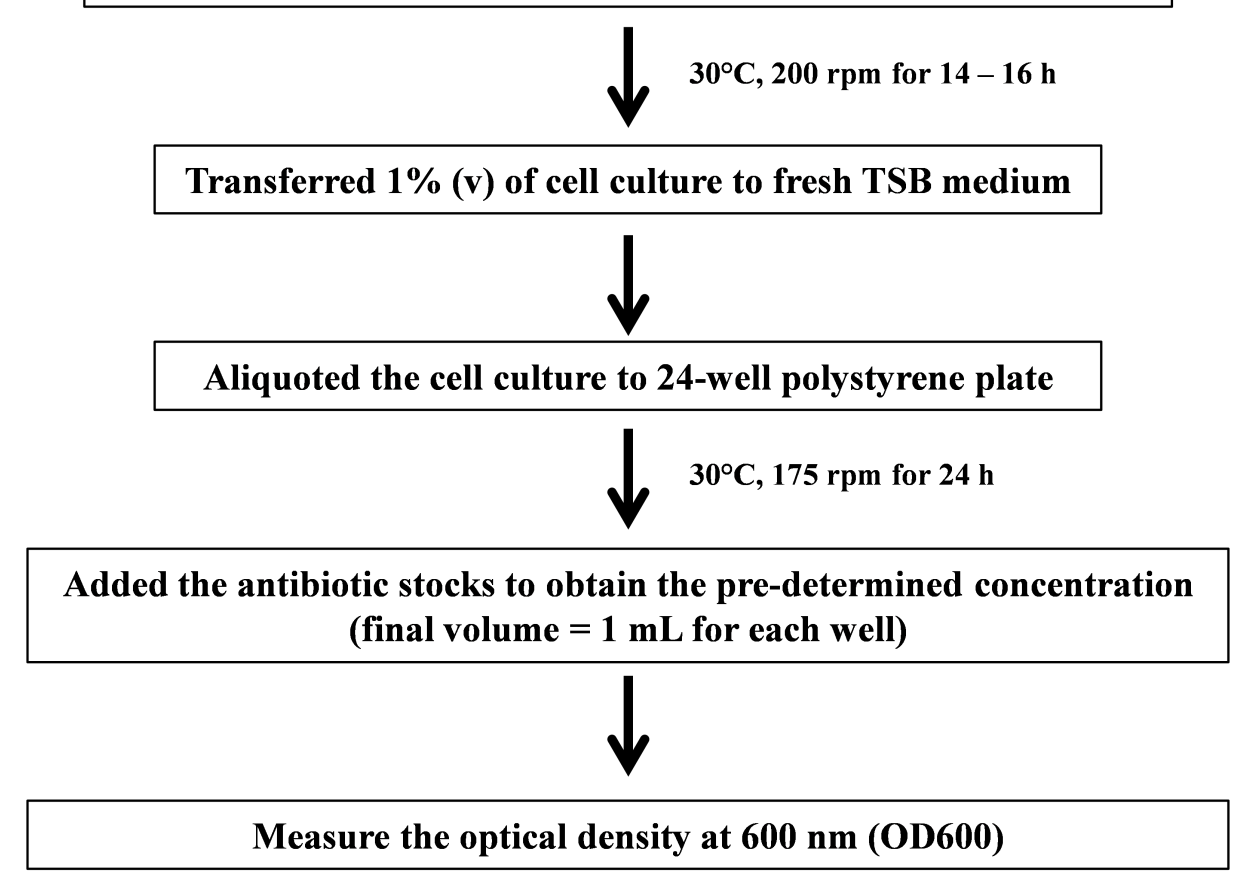

Fig. S1 Determination of antibiotic resistance in the normal and the SCV phenotype. Minimal inhibitory concentration (MIC) of each antibiotic is the lowest concentration that inhibits bacterial growth.

Table S1 Antibiotic MICs for the normal and NZVI-induced SCV phenotype of P. putida F1.

\begin{tabular}{lcr}
\hline \multirow{2}{*}{ Antibiotic } & & MIC $(\mu \mathrm{g} / \mathrm{ml})$ \\
\cline { 2 - 3 } & Normal phenotype & SCV phenotype \\
\hline Gentamicin & 4 & 6 \\
Tetracycline & 2 & 2 \\
Ampicillin & 600 & 200 \\
Chloramphenicol & $>300$ & 150 \\
\hline
\end{tabular}

